\title{
Patterns of Consonant Clusters in Word Initial, Medial, and Final Positions in Yemeni Arabic
}

Muhammed Jubran AL-Mamri

English Department, Hajjah University, Hajjah, Yemen

email: muhammadalmamari@gmail.com

Received:

May 07, 2021

Revised:

May 29, 2021

Accepted:

June 30, 2021

\section{ABSTRACT}

Yemeni Arabic (YA) has a significant number of consonant clusters in word initial, medial, and final positions. However, their frequency of usage is not uniform. This study aims to investigate the patterns of consonant clusters in word initial, medial, and final positions in YA and also to find out the most and least frequent clusters in terms of their percentage. Qualitative and quantitative methods were used in data analysis in this study. All the words were analyzed using Statistical Package for Social Sciences (SPSS). There are features of consonant clusters in Yemeni Arabic which differ from Modern Standard Arabic and some other Arabic dialects. In Yemeni Arabic, there are 29 consonants and 10 vowels, 5 long and 5 short vowels. The maximum number of onset cluster is three (e.g. / Itsu:q/ "she will drive" while coda cluster is two (e.g. /sat'h/ "roof"). Furthermore, the maximum number of medial clusters are also two (e.g. /mux.1s'u/ "sincere". The analysis undertaken will throw light on the frequency and percentages of the occurrences of the consonant clusters on the basis of a word list, which is justified with the help of statistical support.

Keywords: Consonant Clusters; Yemeni Arabic

\section{INTRODUCTION}

There are no initial and medial consonant clusters in Classical Arabic, Modern Standard Arabic and many other Arabic dialects. They are permitted only word- finally (coda position) as in /bint/ "girl", /kalb/ "dog" and /Pard`/ "land". The maximum number of final- consonants clusters in Modern Standard Arabic is two. According to Singh and Singh (1979: 16) consonant cluster is a "string of two or more consonants, it is simply a way of combining the consonant phonemes in a language". (Crystal, 1994, P. 74) says that consonants "are those units of sounds which function at margins of syllables, either singly or in cluster". (Al-jumah, 2008) pointed that initial- consonant clusters in Saudi Arabia (AL-Ahsa) are not allowed, while final consonant clusters are allowed as in /fukk/ "open". (Sameer, 2011, P . 25) asserts that Taizi dialect of Yemeni Arabic has no consonant cluster in the word initial position, but he assert that Taizi dialect has consonant clusters in the word final position as in /bent/ "girl" and $/ t^{2} a b l /$ "drum". (AL-Qahtan, 2014) said that initial and final consonant clusters in Najdi Arabic are not prohibited as in /kla:b.na/ "our dog", /fnu:n/ "arts", /bard/ "cold" and /t falb/ "dog". (Al-Mamri and Shabana, 2017) assert that initial and final 
consonant clusters in Mehri language are allowed as in /nfe:s/ "wide", mla:jket/ "angels", /sowk / "market" and /kawb/ "the wolf".

According to (Abboud, 1979) three- initial consonant clusters occur in Najdi dialect. Moreover, he mentioned that this patterns (three onset clusters) are limited in Najdi dialect such as /str/. (Daana, 2009) pointed that initial- consonant cluster patterns in Classical Arabic are prohibited but in some Arabic dialects such as Palestinian, Cairene and Ammani Arabic onset clusters are not prohibited. She also mentioned that in Ammani Arabic, there are three- initial consonant clusters where the first two sounds (consonants) have to be a geminate whereas the third consonant sound has to be more sonorous than the previous sounds, such as /sswadd/ "became black". (AL-Ghmaiz, 2013) asserts that as a result of first vowel deletion in Najdi Arabic, word-initial consonant clusters are allowed. According to (Al-Mamri, 2018) consonant clusters occur in all positions of word in Zabidi Yemeni dialect and the maximum number of clusters is three- word initial, two- word medial and final.

Yemeni Arabic differs from Modern Standard Arabic in some specific features. One of these features is the phonemic inventory (consonant sounds). All the phonemes that exist in Modern Standard Arabic exist in Yemeni Arabic as well but not all the phonemes that exist in Yemeni Arabic exist in Standard Arabic. In Yemeni Arabic, there are 29 consonants. The table 1 presented below shows the consonants of Yemeni Arabic with examples:

Table 1: Exemplification of Yemeni Arabic consonants

\begin{tabular}{|c|c|c|}
\hline Sound & Word & Gloss \\
\hline$/ \mathrm{b} /$ & /bahr/ & "sea" \\
\hline$/ \mathrm{d} /$ & /da.mu/ & "blood" \\
\hline /q/ & /qa.mar/ & "moon" \\
\hline$/ \mathrm{k} /$ & /ka.ram/ & "generosity" \\
\hline$/ \mathrm{t} /$ & /ta:.ri:x/ & "date" \\
\hline$/ \mathrm{g} /$ & /ga:tl/ & "killer" \\
\hline$/ d^{\mathrm{f}} /$ & /d'a.ru:.ri/ & "necessary" \\
\hline$/ \mathrm{t}^{\mathrm{s}} /$ & $/ t^{\mathrm{s} a}:$ wa:s/ & "peacock" \\
\hline$/ 2 /$ & /2ard / & "land" \\
\hline /ð/ & /ba:ðindza:n/ & "eggplant" \\
\hline$/$ /в / & /ва:lj/ & "expensive" \\
\hline$/ z /$ & /z?aq/ & "he shouted" \\
\hline$/ \theta /$ & /Ougb/ & "hole" \\
\hline /f/ & /fik.reh/ & "an idea" \\
\hline$|\chi|$ & 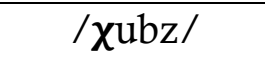 & "bread" \\
\hline$/ \mathrm{s} /$ & /sir.wa:1/ & "trousers" \\
\hline$/ \int /$ & / lisr/ & "poetry" \\
\hline$/ \hbar /$ & /ha:mj/ & "hot" \\
\hline /ð؟/ & /ठ๙ufr/ & "nail" \\
\hline
\end{tabular}




\begin{tabular}{|c|c|c|}
\hline$/ \mathrm{h} /$ & /fosi:.hah/ & "scandal" \\
\hline$/ /$ & /Sagl/ & "mind" \\
\hline$/ d z /$ & /dgaww/ & "they came" \\
\hline$/ \mathrm{s}^{\mathrm{\varsigma}} /$ & /s'sihr/ & "brother-in-law" \\
\hline$/ \mathrm{m} /$ & /ma.ta?/ & "when" \\
\hline$/ \mathrm{n} /$ & /nux.rah/ & "nose" \\
\hline$/ 1 /$ & /lis.Si:b/ & "very playful" \\
\hline$/ \mathrm{r} /$ & /ruk.bah/ & "knee" \\
\hline$/ \mathrm{w} /$ & /wa.si:m/ & "handsome" \\
\hline$/ \mathrm{j} /$ & /ja.ti:m/ & "orphan" \\
\hline
\end{tabular}

Yemeni Arabic has 10 vowels, 5 long and 5 short vowels as exemplified in the following table:

Table 2: Vowels of Yemeni Arabic

\begin{tabular}{|c|c|c|}
\hline Sound & Word & Gloss \\
\hline$/ \mathrm{o} /$ & /hor.mah/ & "woman" \\
\hline /o:/ & /ro:.ћu/ & "soul" \\
\hline$/ \mathrm{a} /$ & / Pa.sal/ & "honey" \\
\hline /a:/ & /ва:lj/ & "expensive" \\
\hline /e/ & /hi.beh/ & "gift" \\
\hline /e:/ & /be:.tu/ & "house" \\
\hline$/ \mathrm{u} /$ & /s'uh.bah/ & "friendship" \\
\hline /u:/ & /mah.bu:s/ & "prisoner" \\
\hline /i/ & /Pis.mak/ & "your name" \\
\hline /I:/ & /dza:.ni:h/ & "wing" \\
\hline
\end{tabular}

This study aims to investigate the occurrence of word consonant clusters (initial, medial, and final) in Yemeni Arabic and also to identify the consonant and vowel sounds of Yemeni Arabic. Moreover to find out the most and least frequent, consonant clusters and its percentage in Yemeni Arabic.

\section{METHOD}

Qualitative and quantitative methods were used in data analysis in this study. Twenty five native Yemeni Arabic speakers were asked to pronounce 250 words that contained all the possible patterns of consonant cluster words that could occur in Yemeni Arabic. All the words (data) of the participants and the researcher which were collected through interviews were written down in International Phonetic Alphabet notation and inserted into the computer to investigate the position, frequency and percentage of consonant clusters in Yemeni Arabic. Then, the words were analyzed by 
Statistical Package for Social Sciences (SPSS) to find out the maximum and minimum frequencies, and percentages of consonant clusters in Yemeni Arabic.

\section{FINDINGS AND DISCUSSION}

\section{Patterns of Consonant Clusters in Yemeni Arabic}

There are three patterns of consonant clusters in Yemeni Arabic (Initial, medial and final). There are altogether four different consonant clusters in the three word positions in Yemeni Arabic. Initial consonant clusters in YA can be classified into two groups: the first group has two - initial consonants as in /s'far/ "yellow", /jhi:n/ "when" and /hmar/ "red", the second group has three - initial consonant clusters as in / tba:n/ "she will appear". Medial consonant clusters in YA can be classified into only one group: two- medial consonants as in /mut ${ }^{\mathrm{f}} \mathbf{2 m u / ~ " f e e d e r " , ~ / m к а j . j m u / ~ " c l o u d y " ~}$ and /mus.kru/ "intoxicant". Final consonant clusters in YA also can be classified into one group: two - final consonants as in /farh/ "happy", /salb/ "difficult" and /nidgm/"star".

\section{Initial - Consonant Clusters in YA}

In Yemeni Arabic, two and three word initial consonant clusters are permitted.

\section{Two - Initial Consonant Clusters in YA}

The environments where the two- initial consonant clusters occurred in Yemeni Arabic are as in the following: stop followed by fricative as in /bxi:.lu/ "stingy", /qPa:.deh/ "bed", /tha:.we?/ "wait", /dha:.nu/ "paint", /t'si:.zu/ "twinge", /tsa:.mah/ "she forgives". Stop followed by nasal as in /bnu/ "son", /?me?/ "blind". Stop followed by another stop as in /gdi:.du/ "new", /kta:.bu/ "book", /dqi:.qah/ "minute", /gda:.ru/ "wall", /Rdaw.wi/ "my enemy", /qta:.lu/ "fighting". Stop followed by lateral as in /glis/ "sit". Stop followed by glide as in /bju:.tu/ "houses".

Nasal followed by stop as in /mkas.sreh/ "having broken", /mdar.rsi:n/ "teachers", /mtar.ga.mu/ "translated", /mkaf.rnu/ "angry (m)". Nasal followed by fricative as in the following:

Table 3: Nasal followed by fricative in Yemeni Arabic

\begin{tabular}{|c|c|}
\hline Word & Gloss \\
\hline /mьај.jmu/ & "cloudy" \\
\hline /mxaj.ja.t $t^{\mathrm{f}} \mathrm{u} /$ & "stitched" \\
\hline /mћaj.jru/ & "confusing" \\
\hline$/ \mathrm{m} \mathrm{ji}: /$ & "walk" \\
\hline$/ \mathrm{m} \int u t^{\mathrm{s}} \cdot \mathrm{t}^{\mathrm{s}} \mathrm{u} /$ & "comb" \\
\hline /mzal.1t $\mathrm{f} \mathrm{u} /$ & "rich (m)" \\
\hline /ms'aw.wri:n/ & "photographer" \\
\hline /msa:.mi:.ru/ & "nails" \\
\hline
\end{tabular}




\begin{tabular}{|c|c|}
\hline$/$ mxað`.ð`ru/ & "greenish" \\
/mzaw.wa.gu/ & "married" \\
\hline
\end{tabular}

Nasal followed by liquid as in /mra:.jeh/ "mirror", Nasal followed by glide as in /mwas s. $^{\varsigma}$ a.lu/ "connected", /mjas.sa.ru/ "facilitated". Fricative followed by stop as in / qqo:1/ "he will say", /s'su:.bah/ "difficulty", /s?a:.deh/ "happiness", / $x \mathrm{t}^{\dagger} \mathrm{u}$ :.bah/ "engagement", /Oqi:lu/ "heavy", /ちku:.meh/ "government", / ga:.?u/ "brave", /fqi:.hah/ "quranic teacher (f)". Fricative followed by nasal as in the following:

Table 4: Fricative followed by nasal in Yemeni Arabic

\begin{tabular}{|c|c|}
\hline Word & Gloss \\
\hline$/$ ðnu/ & "ear" \\
/hmar/ & "red" \\
$/$ hne?/ & "we" \\
$/$ Omu/ & "mouth" \\
$/$ hna:k/ & "there" \\
$/$ s $^{\text {mmar/ }}$ & "tan" \\
$/$ hneh/ & "here" \\
$/$ hza:.mu/ & "belt" \\
$/$ s nag/ & "deaf" \\
$/$ hma:.ru/ & "donkey" \\
\hline
\end{tabular}

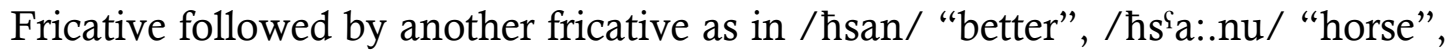
/fð`i:.hah/ "scandal", /s'sa:.ru/ "small (pl)", /hsa:.bu/ "accounting", /z?aq/ "he shouted", / Xii.ru/ "snoring", /s sfar/ "yellow". Fricative followed by lateral as in /s'lą/ bald". Fricative followed by liquid as in /zra:.?ah/ "cultivation". Fricative followed by glide as in / hwal/ "cross-eyed", / wwal/ "left-handed" /swad/ "black".

Glide followed by stop as in /wqaf/ "stand up", /wd'i:fah/ "job", /wga:.?u/ "pain", /wda:.nu/ "cover". Glide followed by Fricative as in /jhi:n/ "when", /wsa:.?u/ "wideness". Liquid followed by stop as in /rqas / "he danced", / $\mathrm{rt}^{\mathrm{\uparrow}} \mathrm{ab} /$ "it became damp", /rqad/ "he slept". Liquid followed by fricative as in /rxi:s $\mathrm{s}^{\mathrm{\zeta}}$ "cheap", /rs'a:.s` u "bullets", /rsamt/ "you drew".

Two- initial consonant clusters in Yemeni Arabic occurred in all the environments but not found in the following environments: stop followed by liquid, nasal followed by lateral, glide followed by nasal or lateral, glide followed by liquid, liquid followed by nasal or lateral, liquid followed by glide.

\section{Three- Initial Consonant Clusters in YA}

Three initial consonant clusters in Yemeni Arabic are formed by combining fricative $/ \mathrm{J} /$ plus $/ \mathrm{t} /$ with any one of the following sounds $(/ \mathrm{s} /, / \mathrm{R} /, / 1 /, / \mathrm{b} /, / \chi /$, $/ \mathrm{r} /, / \mathrm{s}^{\mathrm{s}} /, / \mathrm{m} /$ and $/ \hbar /$ ) as in $/ \int \mathrm{tsu}: \mathrm{q} /$ "she will drive", / $/ \mathrm{t}$ te:t/ "she will come", /Jtluh/ "she will make bread", /Jtba:n/"she will appear", / Itxa:.Jif/ "she will wrestle", 
/ Itro:h/ "she will go", / tn:am/"she will sleep", / $\mathrm{tmu}$ :tu/ "you (pl) will die", / tha:.rib/"she will fight", / Its'a:.rir/"she will wrestle".

Table 5: Patterns of word consonant clusters in YA

\begin{tabular}{|c|c|c|c|}
\hline $\begin{array}{c}\text { Patterns of } \\
\text { word } \\
\text { consonant } \\
\text { clusters }\end{array}$ & Frequency & Percentage & Valid Percent \\
\hline $\begin{array}{c}\text { Two - initial } \\
\text { consonant } \\
\text { clusters /CC-/ }\end{array}$ & 77 & $38.5 \%$ & 38.5 \\
\hline $\begin{array}{c}\text { Three- initial } \\
\text { consonant } \\
\text { clusters } \\
\text { /CCC-/ }\end{array}$ & 10 & $5.0 \%$ & 5.0 \\
\hline $\begin{array}{c}\text { Two- medial - } \\
\text { consonant } \\
\text { clusters /-CC- } \\
\text { / }\end{array}$ & 14 & $7.0 \%$ & 7.0 \\
\hline $\begin{array}{c}\text { Two- final } \\
\text { consonant } \\
\text { clusters /-CC/ }\end{array}$ & 99 & $49.5 \%$ & 49.5 \\
\hline Total & 200 & $100 \%$ & 100.0 \\
\hline
\end{tabular}

Figure 1: Frequencies of initial- consonant clusters in YA

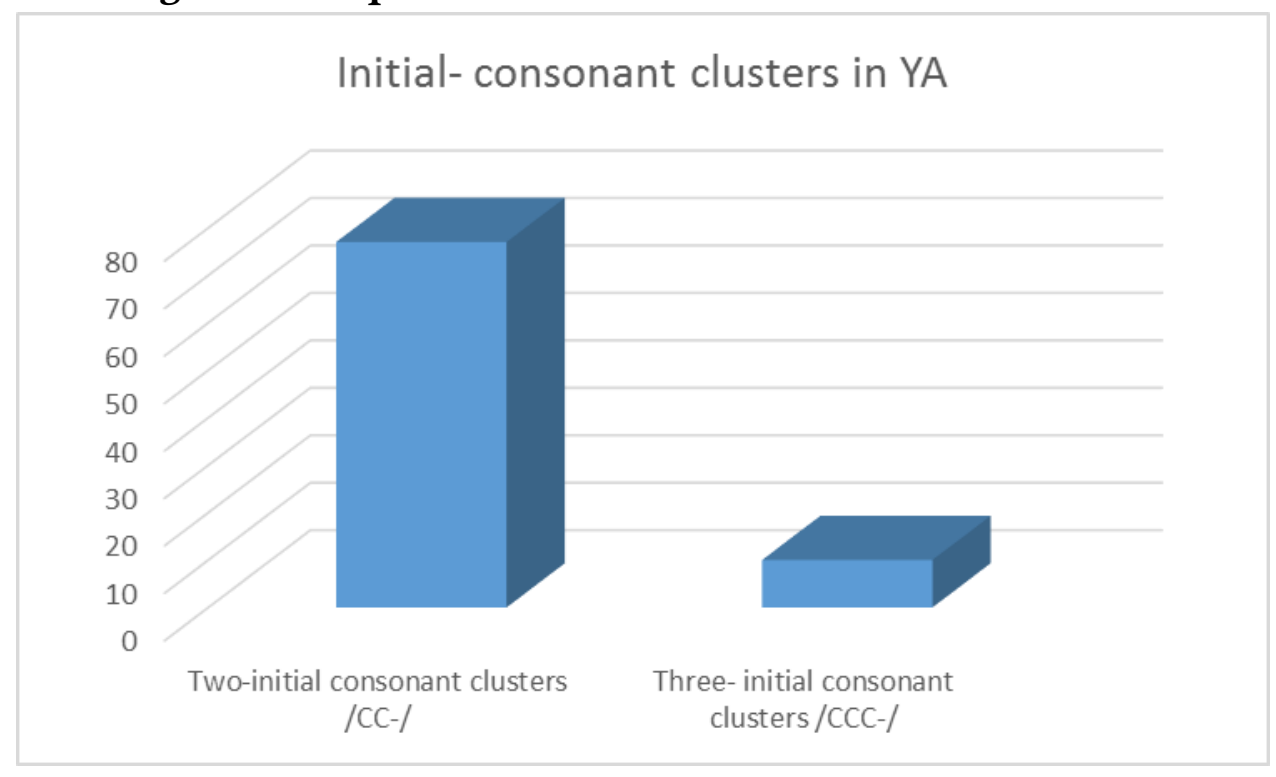

The results as shown in table 5 and figure 1 above indicate that initial consonant cluster words in Yemeni Arabic have two patterns of initial consonant clusters: firstly, two - initial consonants (CC-) as in / $\chi \mathrm{xi} . \mathrm{ru} /$ "snoring" and /sffar/ "yellow". Secondly, three - initial consonants (CCC-) as in /ftn:am/ "she will sleep". 
The percentage and frequency analysis of these 2 patterns of initial - consonant cluster in Yemeni Arabic reveal that two - initial consonant clusters have the highest percentages $38.5 \%$ and show 77 words (frequency) in YA. In addition, three - initial consonant clusters have the least percentages $5.0 \%$ and show 10 words (frequency). To be specific, two - initial consonants have the higher percentages as compared to three initial - consonants in Yemeni Arabic. Two - initial consonants are used more by Yemeni speakers in their speech than three - initial consonants.

\section{Medial - Consonant Clusters in YA}

The patterns of medial consonant clusters in Yemeni Arabic occurred in the following environments. Stop followed by liquid as in /muf.t $\mathrm{r}$ ru/ "not fasting", /mit.kab.bru/ "arrogant", /mus.kru/ "intoxicant". Stop followed by nasal as in /mut'.?mu/ "feeder". Stop followed by glide as in /Pam.dwa:b/ "livestock". Fricative

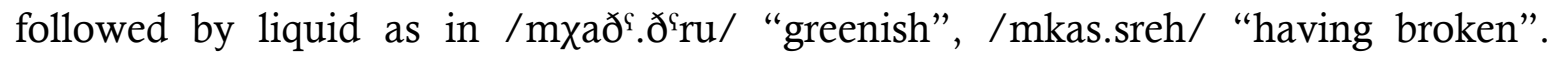
Lateral followed by stop as in /mzal.1t $\mathrm{u}$ / "rich (m)", /mux.1s $\mathrm{s}^{\varsigma} \mathrm{u} /$ "sincere". Lateral followed by nasal as in /mus.lmu/ "muslim (m)". Liquid followed by nasal as in /mkaf.rnu/ "angry (m)". Glide followed by nasal as in /mьaj.jmu/ "cloudy", /mhaw.wmu "feeling hot (m)". Glide followed by liquid as in / mhaj.jru/ "confusing".

Two- media consonant clusters in Yemeni Arabic occurred only in the following environments: Stop followed by liquid, Stop followed by nasal or glide, Fricative followed by liquid, Lateral followed by stop or nasal, Liquid followed by nasal, Glide followed by nasal or liquid.

Figure 2: Frequencies of medial- consonant clusters in YA

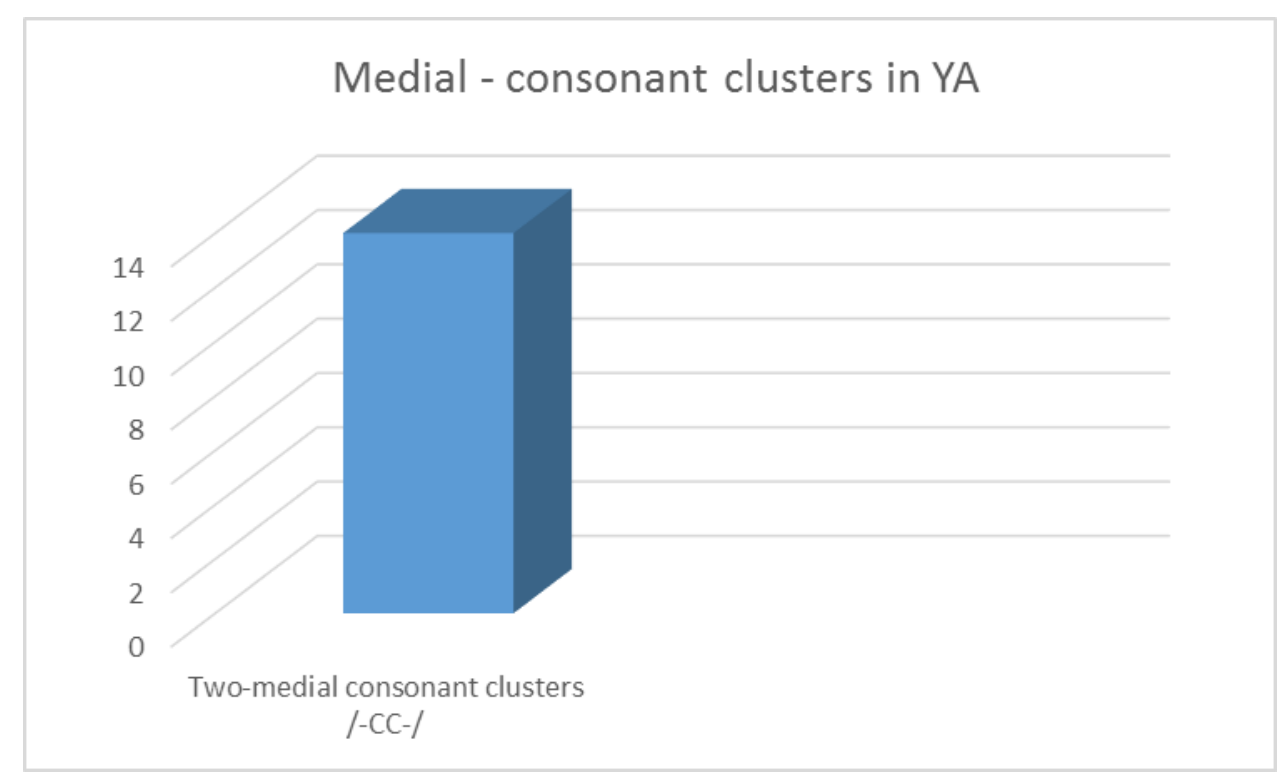

From table 5 and figure 2 above, medial consonant cluster words have only one pattern; two - medial consonants as in /mux.1s $\mathbf{s}^{\mathrm{u}} \mathrm{u}$ "sincere", / mit.kab.bru/ "arrogant"

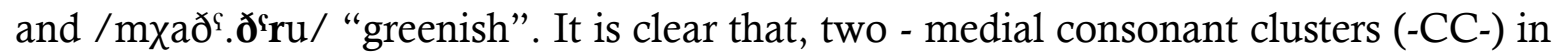
Yemeni Arabic have a minimum percentage of about $7.0 \%$ and show 14 words 
(frequency). Briefly, two - medial consonant cluster words are the least used by Yemeni speakers in their speech.

\section{Final - Consonant Clusters in YA}

In Yemeni Arabic, two and three consonants in word final cluster are permitted. Two- final consonant lusters in YA as in stop followed by fricative /sat $\hbar$ / "roof",

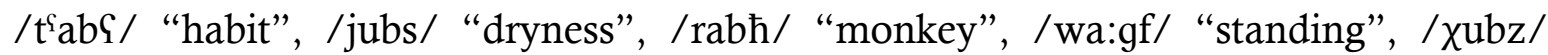
"bread", /kabl/ "ram", /rags / "dance", /Pam.waqt/ "the time". Stop followed by nasal /dign/ "beard", / xa:dm/ "servant". Stop followed by another stop /wagt/ "time", /Ougb/ "hole", /ra:tb/ "salary". Stop followed by lateral /habl/ "rope", /Sag1/ "mind", /ga:tl/ "killer". Stop followed by liquid /gabr/ "grave", /mat'r/ "rain", /bikr/ "a month", /s`adr/ "breast", /s`a:br/ "patient", /sa:kr/ "drunkard". Stop followed by glide /ga:d $\mathrm{d}$ / "judge", /ð`abj/ "gazelle", /na:dj/ "club".

Fricative followed by stop /saSb/ "difficult", /taht/ "under", /waSd/"promise", / uxt $\mathrm{t}^{\mathrm{f}} /$ "stroke" /ha:sd/ "envier". Fricative followed by another fricative /nafs/ "spirit" /nafs/ "soul", /baћ $\theta /$ "research", /wa:ss/ "wide". Fricative followed by nasal /s`ahn/ "dish", /Pism/ "name", /dzism/ "body". Fricative followed by lateral /gufl/ "padlock", /ðৎufr/ "nail", /sahl/ "easy". Fricative followed by liquid /sihr/

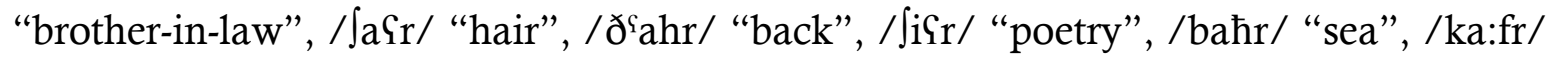
"unbeliever", /mahr/ "marriage settlement", /sihr/ "magic", /nahr/ "river".

Nasal followed by stop /bint/ "girl", /rsamt/ "you drew", /Gind/ "at". Nasal followed by fricative /dams/ "tears", / Jinf/ "lip", / Jams/ "candles", / Jams/ "sun". Nasal followed by liquid /tamr/ "dates", /Sumr/ "age". Nasal followed by glide /ha:mj/ "hot". Lateral followed by stop /kalb/ "dog", /gult/ "I said", /Pam.Өalg/ "the ice", /galb/ "heart". Lateral followed by nasal / Silm/ "science", / (ilm/ "knowledge". Lateral followed by glide /ba:lj/ "old" / ва:lj/ "costly". Liquid followed by stop / Pard`/ "land", / Girg/ "vein", /bard/ "cold" /sa:rg/"thief". Liquid followed by fricative /farh/ "happy", /wirӨ/ "inheritance", /dars/"a lesson". Liquid followed by nasal /ward/ "roses". Liquid followed by glide /ва:lj/ "expensive", /ga:rj/ "reader". Glide followed by stop /bajt/ "house", /fawg/ "up/ above". Glide followed

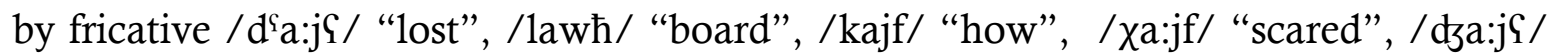
"hungry". Glide followed by nasal /wajn/ "where", /jawm/ "day", /lawn/ "color". Glide followed by lateral /lajl/ "night". Glide followed by liquid /tªjr/ "bird", /za:jr/ "visitor". Two- final consonant clusters in Yemeni Arabic occurred in all the environments except in the following environments: Fricative followed by glide, nasal followed by lateral, lateral followed by fricative or liquid, liquid followed by lateral. 


\section{Figure 3: Frequencies of final- consonant clusters in YA}

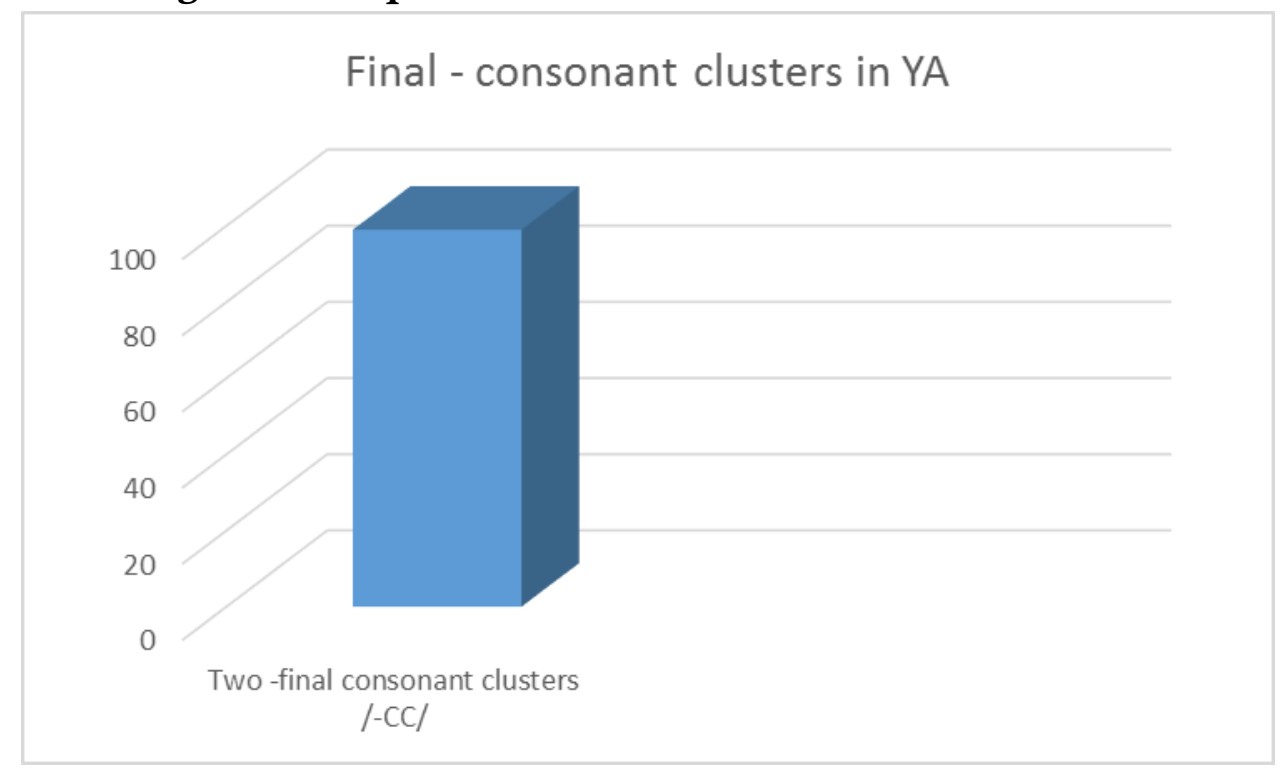

The results indicate that final - consonant cluster words in Yemeni Arabic have

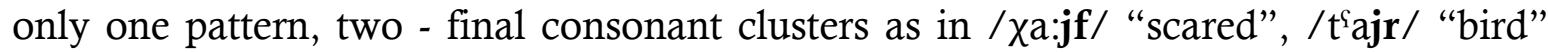
and /Pard"/ "land". The percentage and frequency analysis of this pattern of final consonant cluster reveal that two - final consonant clusters (-CC) have the highest percentage (the most predominant) $49.5 \%$ and show 99 words (frequency) in YA. According to this percentage and frequency of final - consonant clusters in YA, we may conclude that, two - final consonant clusters have the higher percentage as compared to three final - consonant clusters in Yemeni Arabic. Two - final consonant clusters are more used by Yemeni speakers in their speech than three - final consonants.

Table 6: Patterns of word consonant clusters in YA

\begin{tabular}{|c|c|c|c|}
\hline $\begin{array}{c}\text { Patterns of word } \\
\text { consonant clusters }\end{array}$ & Frequency & Percentage & Valid Percent \\
\hline $\begin{array}{c}\text { Initial- consonant } \\
\text { clusters }\end{array}$ & 87 & $43.5 \%$ & 43.5 \\
\hline $\begin{array}{c}\text { Medial- consonant } \\
\text { clusters }\end{array}$ & 14 & $7.0 \%$ & 7.0 \\
\hline $\begin{array}{c}\text { Final- consonant } \\
\text { clusters }\end{array}$ & 99 & $49.5 \%$ & 49.5 \\
\hline Total & 200 & $100 \%$ & 100.0 \\
\hline
\end{tabular}


Figure 4: Frequencies of consonant clusters in YA

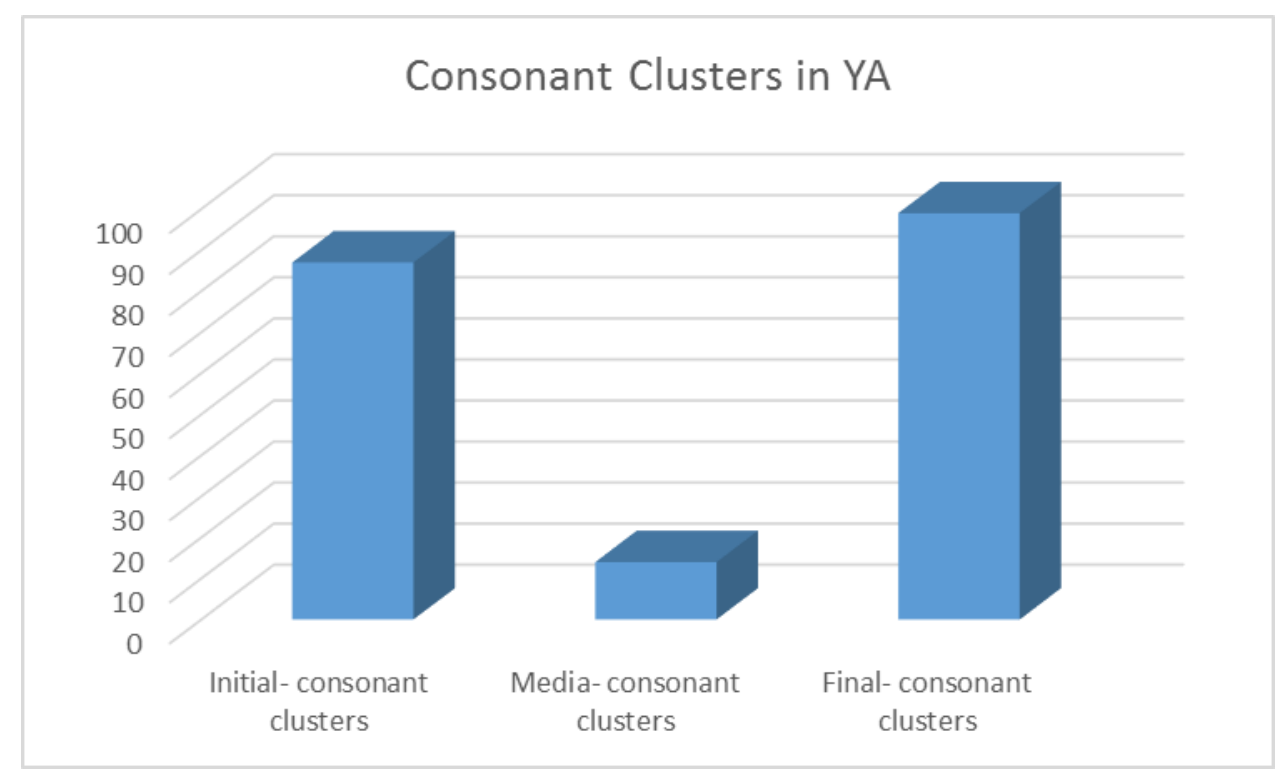

Table 6 and figure 6 above indicate that, there are 4 different consonant clusters distributed in 3 patterns of words in YA (two patterns of initial, one pattern of medial and one pattern of final consonant clusters). It is clear that, the percentage and frequency analysis of these 3 patterns of consonant clusters reveal that final - consonant cluster words have the highest percentage $49.5 \%$ and show 99 words (frequency). This is followed by initial - consonant cluster words which are $43.5 \%$ and show 87 words (frequency). Finally, medial - consonant cluster words have the least percentage $7.0 \%$ and show only 14 words (frequency) in Yemeni Arabic.

\section{CONCLUSION}

The purpose of this work was to investigate the occurrence of consonant clusters in word initial, medial, and final positions in Yemeni Arabic. And also, to find out the most and least frequent consonant clusters and their percentages in Yemeni Arabic. Unlike Standard Arabic and Classical Arabic, the study provided that the patterns of consonant clusters that exist in Yemeni Arabic occurred in all positions of word (initial, medial, and final). In Yemeni Arabic, there are 29 consonants and 10 vowels classified as 5 long and 5 short vowels. Furthermore, in Yemeni Arabic, word consonant clusters occur in all positions of word: firstly, word initial and the maximum number of initial consonants is three. Secondly, word medial and the maximum number of medial consonants is two, finally, word final and the maximum number of final consonant clusters in Yemeni Arabic is two. Initial consonant clusters are formed in Yemeni Arabic by combining fricative $/ \mathrm{J} /$ plus stop $/ \mathrm{t} /$ with any one of the following consonant sounds $\left(/ \mathrm{s} /, / \mathrm{P} /, / \mathrm{l} / \mathrm{h} / \mathrm{b} /, / \chi /, / \mathrm{r} /, / \mathrm{s}^{\mathrm{s}} /, / \mathrm{m} /\right.$ and $\left./ \mathrm{h} /\right)$. The percentage and frequency analysis of these 3 patterns of consonant clusters reveal that final - consonant cluster words have the highest percentage $49.5 \%$ and show 99 words 
(frequency). This is followed by initial - consonant cluster words which are $43.5 \%$ and show 87 words (frequency). Finally, medial - consonant cluster words have the least percentage $7.0 \%$ and show only 14 words (frequency) in Yemeni Arabic.

\section{REFERENCES}

Abboud, P. (1979). The verb in northern Najdi Arabic. Bulletin of the School of Oriental and African Studies, 42. (3) 467-499.

AL-Ghmaiz, B. (2013). Word - initial consonant cluster patterns in the Aeabic Najdi dialect. M.A theses. Southern Illinois University Carbondale.

AL-Mamri, Muhammed, and Shabana Hameed. (2017). Consonant cluster and syllable structure in Mehri language. International Journal of Scientific and Research Publications, 7(2): 242-248.

AL-Mamri, M. (2018). Syllable structure and word stress in Hajji and Hudaidi Yemeni dialects of Arabic in the light of optimality theory. $\mathrm{PhD}$ thesis. Aligarh Muslim University (AMU). India.

Al-jumah, Abdullah. (2008). The syllable shape of Al-Ahsa dialect: An OT perspective. Poznań Studies in Contemporary Linguistics 44(2):155-177.

Al-Qahtani, Mufleh. (2014). Syllable structure and related processes in optimality theory: An examination of Najdi Arabic. PhD thesis. Newcastle University.

Crystal, D. (1994). A Dictionary of linguistics and phonetics. 3rd ed. Oxford: Blackwell.

Daana, H. (2009). The development of consonant cluster, stress and plural nouns in Jordanian Arabic child language. (Unpublished doctoral thesis). University of Essex, London.

Sameer, Abdulrazzaq. (2011). Syllable structure of Taizi Yemeni dialect of Arabic: An optimality theory perspective. MA dissertation. School of Language Science, the English and Foreign Languages University (EFL-U), Hyderabad, India.

Singh, K. \& Singh, S. (1979). Phonetics: Principles and practice. Baltimore: University Park Press. 